Research Article

\title{
Tripartite Evolutionary Game and Simulation Analysis of Coal Mining Safe Production Supervision under the Chinese Central Government's Reward and Punishment Mechanism
}

\author{
Kui Zhou (D), 1 Qi Wang, ${ }^{2}$ and Junnan Tang ${ }^{3}$ \\ ${ }^{1}$ School of Public Finance and Taxation, Zhongnan University of Economics and Law, Wuhan 430070, China \\ ${ }^{2}$ School of Economics, Fudan University, Shanghai 200082, China \\ ${ }^{3}$ Central China Securities Research Institute, Shanghai 200082, China
}

Correspondence should be addressed to Kui Zhou; kuizhou@stu.zuel.edu.cn

Received 4 August 2021; Revised 12 October 2021; Accepted 5 November 2021; Published 20 November 2021

Academic Editor: Xinyu Wang

Copyright (c) 2021 Kui Zhou et al. This is an open access article distributed under the Creative Commons Attribution License, which permits unrestricted use, distribution, and reproduction in any medium, provided the original work is properly cited.

In recent years, although coal mine accidents in China have decreased, they still occur frequently. Most previous studies on the evolutionary game of safety mining are limited to a focus on system dynamics and two-party game problems and lack a spatial graphic analysis of strategy evolution. The parameters adopted are too few, and the influencing factors considered are too simple. The purpose of the paper is to introduce more parameters to study which will have an important impact on the strategy choices of participants and the evolution path of the strategy over time. We construct a tripartite evolutionary game model of coal mining enterprises, local governments, and central governments. As our method, a payment matrix of participants and replicated dynamic equations is established, and we also implement parameter simulation in MATLAB. In summary, we found that the reward and punishment mechanism plays an important role in safe coal mining. Specifically, (1) intensifying rewards and penalties for coal mining enterprises and local governments will help encourage coal mining enterprises to implement safe production measures and local governments to implement central government safety supervision policies. However, increased rewards will reduce central government's willingness to adopt incentive strategies. (2) The central government's reward for coal mining enterprises' safe production must be greater than the increased cost of safe production to encourage enterprises to implement such production. Economic incentives for local governments must be greater than the benefits of rent-seeking; only then will local governments choose to strictly implement supervision policies. (3) Increasing sales revenue and rent-seeking costs of coal mining enterprises can also encourage them to implement safe production. Therefore, a well-designed reward and punishment mechanism will change the behaviour of coal enterprises and improve the probability of safe production. The research presented in this paper further works on improving safe coal mining production and designing reasonable reward and punishment mechanisms.

\section{Introduction}

In recent years, with the rapid development of China's economy, the demand for energy resources such as coal has become increasingly intense. China's coal production accounts for $46.4 \%$ of the world's production, ranking first in the world for many years [1]. However, the death toll of Chinese coal mine workers accounts for approximately $70 \%$ of the total death toll worldwide [2]. In terms of coal mine safety, Australia far exceeds China, and Chinese miners are powerless in terms of safety supervision [3]. The limitations of China's coal mine safety supervision system are a reason for the frequent occurrence of safety accidents [4]. China's new coal mine safety management regulations will have a significant impact on coal mine safety [5]. The operation mode of mine management and the employed system of reward and punishment help promote safe mine production [6]. The vertical supervision system of safe coal production in China plays an important role in improving coal mine safety, and an increase in per capita supervision frequency 
can promote the supervision performance of the National Mine Safety Administration [7]. Relying on unlimited increases in rewards and penalties alone cannot encourage enterprises to invest in mine safety.

Scholars have gradually used game theory to analyse the stakeholders of safe coal mine production, including the central government, local governments, coal mining enterprises, and miners [8, 9]. However, their works largely assume that the subjects participating in the game are completely rational. The evolutionary game, which originated in the field of population biology in the 1980s, considers the irrationality of players and the importance of time factors and provides a new analytical paradigm for safe coal mine production [10-12]. Therefore, although some papers have explored this problem, deficiencies in model design and specific simulation analysis methods remain, so it is necessary to design a more practical model.

The purpose of this paper is to design a more practical model to identify the factors that affect the safe production of coal enterprises, conditions under which reward and publishment mechanisms can work and strategy changes over time, and provide a reference for the reasonable design of safe production reward and punishment systems. This paper makes the following contributions. (1) We establish a replicated dynamic equation and draw a diagram of the corresponding strategy to prove the economic rationality of game participants. (2) We use a spatial three-dimensional diagram to show the impact of the change in parameters on the strategy. (3) We introduce more parameters, which is more in line with real environments. (4) We strive to make the results of this paper conform to common principles of economics and prove the rationality of our conclusions through rigorous mathematics. In terms of our method, we establish a tripartite evolutionary game model, a payment matrix of participants and replicated dynamic equations, and then we conduct a parameter simulation in MATLAB. Figure 1 shows the research content framework of this paper. How does the reward and punishment mechanism affect the safe production of coal enterprises? What conditions are required for the reward and punishment mechanism to work? Are these conditions applicable to local governments? We explore these problems in the following section.

\section{Literature Review}

At present, although some studies have used the evolutionary game method to study safe coal mining production, there is still room for the work conducted in our study. Evolutionary games are an application of game theory in the field of biological evolution and are now widely used in economics and management. Smith was the first to study evolutionary games [13]. He applied an evolutionary game to the prisoner's dilemma. Later, some scholars extended the model $[14,15]$ to simulate the cooperative evolution of biological populations. The study of the relationship between supply and demand in the supply chain has been extended to game theory [16]. Evolutionary games are also used to study the educational significance of online cooperative groups [17]. Evolutionary game theory holds that game subjects have bounded rationality, it is difficult to choose the optimal strategy of a single game, and the game subject achieves high efficiency through continuous trial and error and imitation to achieve evolutionary stability [18]. Some papers have extended evolutionary game models to different cases [19-21].

Early scholars applied evolutionary games to safe coal mine production; they mainly analysed the game between regulators and coal mining enterprises and identified insufficient investment in coal mine safety as the main cause of frequent accidents [22-24]. Some research studies have mainly focused on two-party evolutionary games [25-29]. However, the involved game participants are different; some games occur between coal mines, and some occur between coal mines and miners. There are relatively few papers on tripartite games [30-32]. The content of existing work has some drawbacks, and there has been a lack of rigorous mathematical demonstration [33, 34]. Some studies show deficiencies in the impact analysis of parameter changes [35]. Increasing rewards and punishments can quickly reduce unsafe behaviours in a static game [36, 37], but dynamic analysis is lacking. China's fiscal decentralization system leads to a tendency for local governments to favour polluting enterprises [38]. When the probability of illegal operation is reduced to a certain extent, the probability of supervision will gradually decrease [39]. However, the players of the game are coal miners and safety regulators. The effective supervision of coal miners' emotions is an important means to achieve coal mine safety [40]. When certain conditions are met, all parties in the game can reach the ideal stable state [41].

Different papers have researched different issues surrounding coal enterprises; there has been research on the resource integration of coal enterprises [42], overcapacity in the coal industry [43], and policy impacts on strategy choices [44]. Regarding the reward and punishment mechanism, some scholars believe that reasonable reward and punishment can stimulate the safe production behaviour of coal enterprises; however, others hold that excessive rewards and punishments may have unexpected consequences that are often difficult for small- and medium-sized coal mines to adapt to [45-47]. The central government has formulated a safety supervision policy, local governments are responsible for implementing it, and enterprises are responsible for safe production [48]. In the population evolution game, individuals imitate and learn from other individuals, compare their payoff changes, and then adjust their strategies, resulting in a feedback effect. Many scholars have studied the stability of the equilibrium point by means of system dynamics [49-51]. However, this method is used too frequently. In this paper, we use MATLAB and Visio for our analysis and adopt a new approach.

\section{Hypothesis and Model Establishment}

Evolutionary game theory was developed to overcome the drawbacks of traditional games and analyse game players with limited rationality and dynamic games [52-54]. Replicator dynamics identify how pure strategies that lead to 


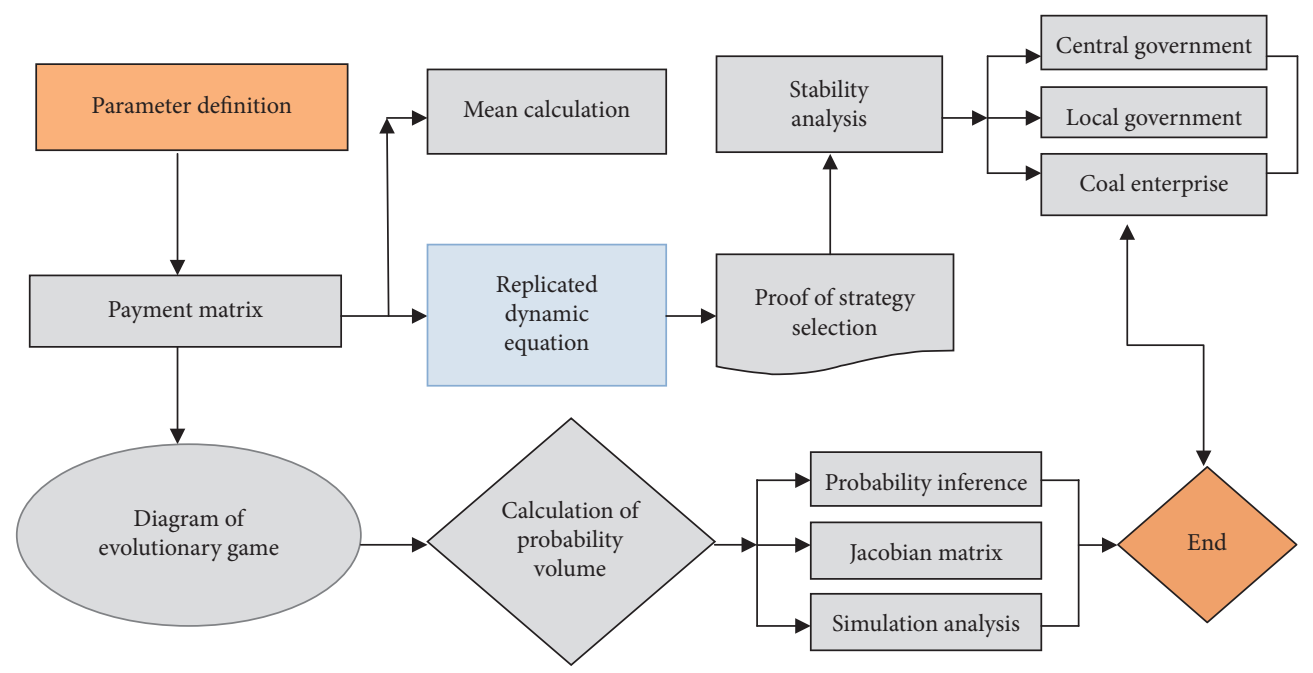

FIgURE 1: Research framework of this paper.

changes in population share and evolve over time [55]. The most likely outcome of the evolutionary game is determined by the completeness of information obtained by participants and expectations of other participants' strategies $[56,57]$.

3.1. Model Hypothesis. Referring to the relevant literature $[25,29,33,58,59]$, this paper establishes a tripartite evolutionary game model of the central government, coal production enterprises, and local governments. To analyse the existence of the equilibrium point in the evolutionary game and the relationships between various factors, we make the following hypotheses.

Hypothesis 1. The main players of the game are the central government, coal enterprises, and local governments. They are bounded rational, so their strategies gradually reach an evolutionarily stable state over time.

Hypothesis 2. As coal mining enterprises need to increase their investment in safe production equipment and safety supervision personnel, an increase in these additional investments will increase the production cost of the enterprises. Due to their pursuit of profit maximization, coal mining enterprises show insufficient willingness to invest in safety. Therefore, it is necessary for the government to supervise coal enterprises. The game strategy set of a coal enterprise is as follows: $\delta=\left(\delta_{1}, \delta_{2}\right)=$ (safe production, unsafe production). The probability of adopting safe production is $x$, and the probability of adopting unsafe production is $1-x, x \in[0,1]$. In China, there are countless relationships between local governments and coal enterprises. The coal industry is in many cases central to local economies, has paid considerable taxes to local governments, and has created many employment opportunities. Therefore, local governments tend to protect these coal enterprises. However, in recent years, China's central government has increased its supervision of coal mine safety. The National Mine Safety Administration was set up by the central government, and the Provincial Mine Safety Administration was set up by local governments. Local governments are responsible for implementing the safety supervision policy of the central government. Therefore, the local government undertakes the dual tasks of economic development and coal mine safety supervision. Thus, the game strategy set of local governments is as follows: $\sigma=\left(\sigma_{1}, \sigma_{2}\right)=($ refuse rent - seeking, accept rent - seeking). The probability of a local government choosing $\sigma_{1}$ is $y$, and the probability a local government choosing $\sigma_{2}$ is $1-y$. In China, the central government is responsible for formulating coal mine safety supervision policy and supervising the implementation of safety supervision policy by local governments. The strategic set of the central government is as follows: $\lambda=\left(\lambda_{1}, \lambda_{2}\right)=$ (strict supervision, loose supervision). The probability of the central government choosing $\lambda_{1}$ is $z$, and the probability of the central government choosing $\lambda_{2}$ is $1-z$.

Hypothesis 3. We assume the sales revenue of coal enterprises in the market to be $\pi_{e}$. We assume that the sales revenue of coal enterprises brought by safe and unsafe production is the same, and this assumption is reasonable in a fully competitive market. The difference between safe and unsafe production lies in the associated cost. Because safe production must increase the input of related equipment and personnel, the cost of safe production is relatively high, while the cost of unsafe production is relatively low. Therefore, we assume that the cost of safe production is $C_{e h}$, while the cost of unsafe production is $C_{e l}$, assuming that $C_{e h}>C_{e l}$ and $\Delta C_{e}=C_{e h}-C_{e l}$.

Hypothesis 4. The strategies of local governments are to refuse and accept rent-seeking. We assume that when coal enterprises choose to carry out safe production, it is unnecessary for them to collude with local governments. Only when coal enterprises choose unsafe production will coal enterprises choose to corrupt local government departments to avoid punishment from local regulatory authorities. We 
assume that a local government's revenue from the production of coal enterprises is $\pi_{l}$. The local government's cost of strictly implementing supervision policy is $C_{l}$. Assuming that if the local government accepts rent-seeking from coal enterprises and does not strictly implement the central government's safety supervision task, it does not need to pay the extra cost.

Hypothesis 5. The central government's strategy is to apply strict and loose supervision of local governments and coal enterprises. Assuming that the cost of strict supervision by the central government is $C_{c}$, the benefit of safe production by coal enterprises for the central government is $\pi_{c}$. The reward given by the central government to coal enterprises for safe production is $R_{e}$. The reward given by the central government to the local government that refuses corruption and rent-seeking is $R_{l}$, the punishment of the local government's acceptance of corruption and rent-seeking is $F_{l}$, and the punishment imposed by the central government on coal enterprises that do not use a safe production method is
$F_{e}$. The rent-seeking cost of the coal enterprise is $B_{e}$, and the cost of the central government maintaining social stability and rectifying the coal market is $D_{g}$. Table 1 lists relevant parameters of the model.

3.2. Establishment of the Model. We establish a tripartite evolutionary game model of coal enterprises, central government, and local governments. By analysing the strategy of all parties involved in the game, the game payment matrix shown in Table 2 is established.

\section{Model Analysis}

4.1. Analysis of the Evolutionary Equilibrium Strategy of Safe Production by CoalEnterprises. We assume that the expected income from safe production is $E_{11}$, the expected income from unsafe production is $E_{12}$, and the total average expected income is $E_{1}$.

$$
\begin{aligned}
E_{11}= & y z\left(\pi_{e}-C_{e h}+R_{e}\right)+y(1-z)\left(\pi_{e}-C_{e h}\right)+(1-y) z\left(\pi_{e}-C_{e h}+R_{e}\right)+ \\
& (1-y)(1-z)\left(\pi_{e}-C_{e h}\right)=\pi_{e}-C_{e h}+z R_{e}, \\
E_{12}= & y z\left(\pi_{e}-C_{e l}-F_{e}\right)+y(1-z)\left(\pi_{e}-C_{e l}\right)+(1-y) z\left(\pi_{e}-C_{e l}-F_{e}-B_{e}\right)+(1-y)(1-z)\left(\pi_{e}-C_{e l}-B_{e}\right) \\
= & \pi_{e}-C_{e l}-z F_{e}-(1-y) B_{e}, \\
E_{1}= & x E_{11}+(1-x) E_{12} .
\end{aligned}
$$

The replicated dynamic equation of the coal production enterprise is as follows:

$$
\begin{aligned}
F(x)= & \frac{\mathrm{d} x}{\mathrm{~d} t}=x\left(E_{11}-E_{1}\right)=x(1-x)\left[z\left(R_{e}+F_{e}\right)\right. \\
& \left.+C_{e l}-C_{e h}+(1-y) B_{e}\right] .
\end{aligned}
$$

The first derivative of the replicated dynamic equation of the coal enterprise is as follows:

$$
\begin{aligned}
& \frac{\partial(F(x))}{\partial x}=(1-2 x)\left[z\left(R_{e}+F_{e}\right)+C_{e l}-C_{e h}+(1-y) B_{e}\right], \\
& \text { Let } H(z)=z\left(R_{e}+F_{e}\right)+C_{e l}-C_{e h}+(1-y) B_{e} .
\end{aligned}
$$

According to the stability principle of the differential equation, the following conditions are required for the coal enterprise to achieve stable status: $F(x)=0 ; \partial F((x)) / \partial x<0$. Because $\partial(H(z)) / \partial(z)=R_{e}+F_{e}$ and coefficient $R_{e}+F_{e}>0$ and $\partial(H(z)) / \partial(z)>0, H(z)$ is a negative function of $z$. When $z=C_{e h}-C_{e l}-(1-y) B_{e} / R_{e}+F_{e}=z^{*}, \quad H(z)=0$, and $F(x) \equiv 0$, all values of $x$ will bring the coal enterprise to an evolutionarily stable state. When $z<z^{*}$ and $H(z)<0$, $x=0$ is a stable strategy for the coal enterprise. In contrast, when $z>z^{*}$ and $H(z)>0, x=1$ is a stable strategy for the coal enterprise; that is, when the probability of the central government choosing strict supervision is high, coal enterprises tend to carry out safe production. A diagram of the coal enterprise is shown in Figure 2.

Figure 2 shows that the probability of coal enterprises adopting unsafe production has a volume of $P_{1}$, and we use $V_{P_{1}}$ to express this value. This status indicates that $X=0$ is the evolutionarily stable state of the coal enterprise when $z<z^{*}$. In other words, adopting unsafe production is the evolutionarily stable strategy of coal enterprises. The volume of $P_{2}$ is the probability of stable safe production for coal enterprises, and we use $V_{P_{2}}$ to express this value.

$$
V_{P_{1}}=\int_{0}^{1} \int_{0}^{1} \frac{z\left(R_{e}+F_{e}\right)+C_{e l}-C_{e h}+B_{e}}{B_{e}} \mathrm{~d} z \mathrm{~d} x=-\frac{2\left(C_{e l}-C_{e h}+B_{e}\right)+R_{e}+F_{e}}{2 B_{e}}, \quad V_{P_{2}}=1-V_{P_{1}} .
$$


TABLE 1: Relevant parameters of the tripartite evolutionary game.

\begin{tabular}{lc}
\hline Parameter & Explanation of parameter's meaning \\
\hline$\pi_{e}$ & Sales revenue of coal enterprise \\
$C_{e h}$ & Cost of safe production of coal enterprise \\
$C_{e l}$ & Cost of unsafe production of coal enterprise \\
$R_{e}$ & Rewards given to coal enterprise for safe production \\
$\pi_{l}$ & Local government's economic benefit from coal production \\
$C_{l}$ & Cost of local government's strict supervisory policy \\
$R_{l}$ & Reward for local government's refusal of rent-seeking \\
$\pi_{c}$ & Central government's benefit from safe production \\
$C_{c}$ & Cost of central government's strict supervision \\
$F_{l}$ & Penalty for local government's acceptance of rent-seeking \\
$F_{e}$ & Penalty for coal enterprise's unsafe production \\
$B_{e}$ & Rent-seeking cost of coal enterprise \\
$D_{g}$ & Central government 's cost of maintaining social stability and reorganizing the coal market \\
\hline
\end{tabular}

TABLE 2: Tripartite evolutionary game payment matrix of the model.

Central government

Local government

Strict supervision Loose supervision

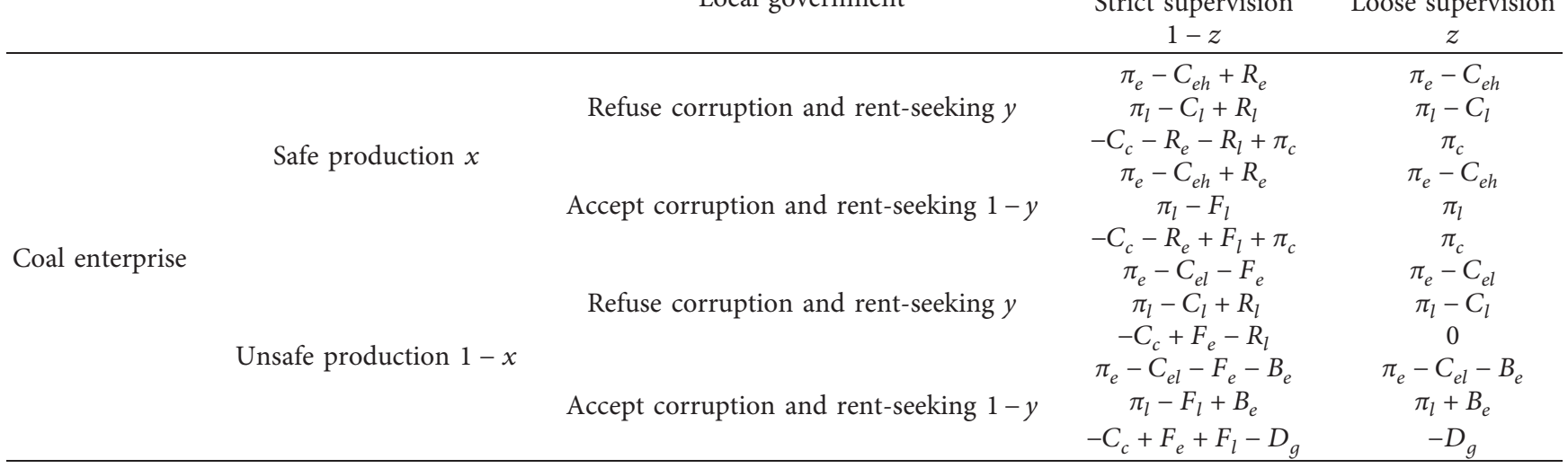
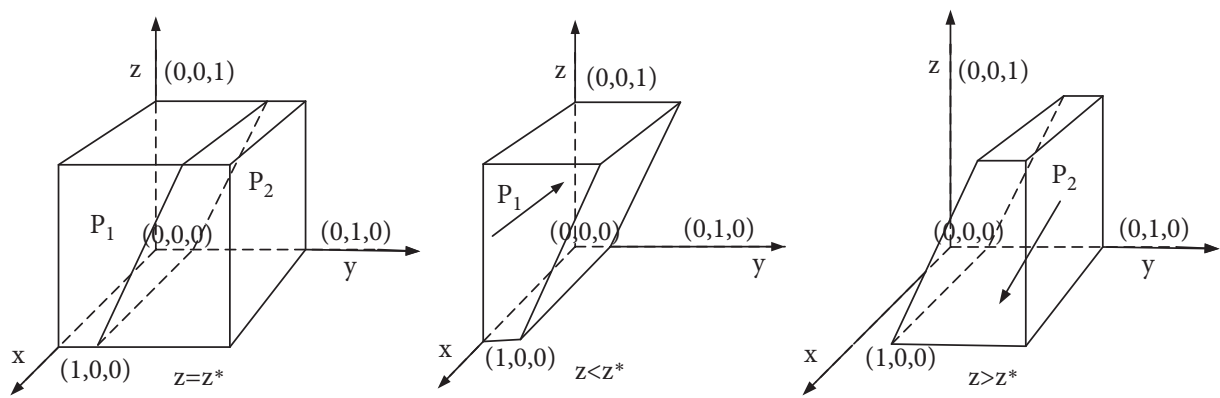

FIGURE 2: Coal enterprise strategy diagram.

Inference 1. The probability of a coal enterprise's safe production is positively correlated with the central government's reward and punishment for safe production, but it is negatively correlated with the costs of safe production and rent-seeking. According to probability formula $V_{P_{2}}$, the safe production of the coal enterprise, and the first-order 
derivation of the reward, penalty and rent-seeking of the local government according to the central government can be obtained as follows:

$$
\begin{aligned}
& \frac{\partial V_{P_{2}}}{\partial R_{e}}>0, \\
& \frac{\partial V_{P_{2}}}{\partial F_{e}}>0, \\
& \frac{\partial V_{P_{2}}}{\partial B_{e}}<0, \\
& \frac{\partial V_{P_{2}}}{\partial C_{e h}}<0 .
\end{aligned}
$$

Therefore, there is a positive correlation between reward and safe production. The same relationship also exists in the punishment and rent-seeking cost of coal enterprises. An increase in the value will increase the probability of coal enterprises carrying out safe production. The central government should strengthen policy promotion to increase rewards and punishments for unsafe production behaviour, improve the income of coal enterprises, and reduce the cost of safety investment to encourage coal enterprises to carry out safe production.

Inference 2. The probability of safe production is positively correlated with the probability of the local government refusing rent-seeking. The value is also positively correlated with the probability of the central government's strict supervision. When $z<z^{*}$ and $H(z)<0, x=0$ is the stable strategy of the coal enterprise. In contrast, when $z>z^{*}$ and $H(z)>0, x=1$ is the stable strategy of the coal enterprise, indicating that the more likely the central government is to reward and punish, the greater the probability of the coal enterprise choosing safe production becomes. This shows that the central government needs to strengthen incentive policies to motivate coal enterprises to carry out safe production.

4.2. Analysis of the Local Government's Evolutionary Equilibrium Strategy. We assume that the expected return of the local government's choice to reject rent-seeking is $E_{21}$. The expected return of local governments choosing to accept rent-seeking is $E_{22}$, and the total average expected return is $E_{2}$.

$$
\begin{aligned}
E_{21}= & X Z\left(\pi_{l}-C_{l}+R_{l}\right)+X(1-Z)\left(\pi_{l}-C_{l}\right)+(1-X) Z\left(\pi_{l}-C_{l}+R_{l}\right)+ \\
& (1-X)(1-Z)\left(\pi_{l}-C_{l}\right)=\pi_{l}-C_{l}+Z R_{l}, \\
E_{22}= & X Z\left(\pi_{l}-F_{l}\right)+X(1-Z)\left(\pi_{l}\right)+(1-X) Z\left(\pi_{l}-F_{l}+B_{e}\right)+ \\
& (1-X)(1-Z)\left(\pi_{l}+B_{e}\right)=\pi_{l}-Z F_{l}+(1-X) B_{e}, \\
E_{2}= & y E_{21}+(1-y) E_{22} .
\end{aligned}
$$

The replicated dynamic equation of the local government is as follows:

$$
F(y)=\frac{\mathrm{d} y}{\mathrm{~d} t}=y\left(E_{21}-E_{2}\right)=y(1-y)\left[z\left(R_{l}+F_{l}\right)-(1-x) B_{e}-C_{l}\right]
$$

The first derivative of the local government's replicated dynamic equation is as follows:

$$
\frac{\partial(F(y))}{\partial y}=(1-2 y)\left[z\left(R_{l}+F_{l}\right)-(1-x) B_{e}-C_{l}\right]
$$

Let

$$
G(z)=z\left(R_{l}+F_{l}\right)-(1-x) B_{e}-C_{l} .
$$

According to the stability principle of the differential equation, the probability of the local government strictly implementing the central government's safe supervision policy $y$ needs to meet the following conditions to achieve stability: $\quad F(y)=0 ; \quad \partial(F(y)) / \partial y<0 . \quad$ Because
$\partial(G(z)) / \partial(z)=R_{l}+F_{l}$ and $R_{l}+F_{l}>0, \partial(G(z)) / \partial(z)>0$ and $G(z)$ is an increasing function of $z$. When $x=B_{e}-z\left(R_{l}+F_{l}\right)+C_{l} / B_{e}=x^{*}, G(z)=0$, and $F(y) \equiv 0$, then all values of $y$ will bring the local government to an evolutionarily stable state. When $x<x^{*}$ and $G(z)<0, y=1$ is the stable state of the local government. In contrast, when $x>x^{*}$ and $G(z)>0, y=0$ is the stable state of the local government; that is, when the probability of the coal enterprise choosing safe production is low, the local government tends to refuse rent-seeking and strengthen the supervision of safe production. The evolutionary diagram of the local government is shown in Figure 2.

Figure 3 shows that the probability of local governments rejecting rent-seeking can be represented by the volume of 

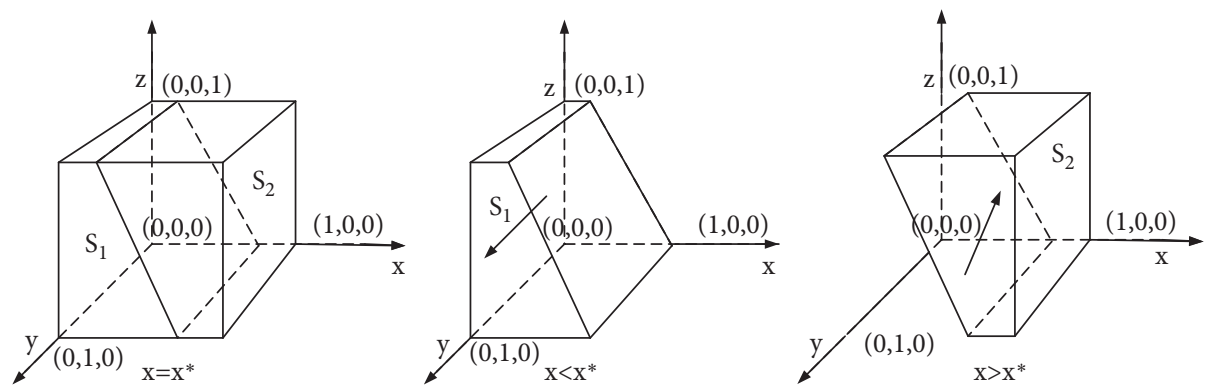

FIGURE 3: Local government strategy diagram.

part $S_{1}$. When $x<x^{*}, y=1$ is the evolutionarily stable strategy of the local government. In other words, it is the evolutionary strategy of the local government to strictly supervise coal enterprises and refuse rent-seeking. The volume of $S_{2}$ is the probability of local governments choosing to accept rent-seeking. $V_{S_{1}}$ can be calculated as follows:

$$
V_{S_{1}}=\int_{0}^{1} \int_{0}^{1} \frac{B_{e}-z\left(R_{l}+F_{l}\right)+C_{l}}{B_{e}} \mathrm{~d} z \mathrm{~d} y=\frac{2\left(B_{e}+C_{l}\right)-\left(R_{l}+F_{l}\right)}{B_{e}}, \quad V_{S_{2}}=1-V_{S_{1}} .
$$

Inference 3. The probability of the local government rejecting rent-seeking is positively correlated with the central government's reward and the punishment for accepting rent-seeking. It is negatively correlated with the cost of strict regulation enforcement and the level of rentseeking by coal enterprises.

According to the probability formula of the local government's implementation of strict regulatory policy $V_{S_{2}}$, the first-order derivation of the central government's reward and punishment of the local government, the cost of the strict implementation of regulatory policy, and the rentseeking of coal enterprises can be obtained:

$$
\begin{aligned}
& \frac{\partial V_{S_{2}}}{\partial R_{l}}>0, \\
& \frac{\partial V_{S_{2}}}{\partial F_{l}}>0, \\
& \frac{\partial V_{S_{2}}}{\partial C_{l}}<0, \\
& \frac{\partial V_{S_{2}}}{\partial B_{e}}>0 .
\end{aligned}
$$

Therefore, the increase in the central government's reward $R_{l}$ and the penalty for accepting rent-seeking $F_{l}$ will increase the probability of the local government strictly implementing regulatory policy. The central government should strengthen policy promotion, increase incentives and penalties for local governments to strictly implement the policy, and reduce the cost of local government's strict implementation of supervision policy to encourage local governments to strictly implement safe coal production policies.

Inference 4. The probability of the local government strictly implementing the central government's supervision policy is positively related to the probability of the coal enterprise carrying out safe production. When $x<x^{*}$ and $G(z)<0$, $y=1$ is the stable strategy of the local government. In contrast, when $x>x^{*}$ and $G(z)>0, y=0$ is the stable strategy of the local government.

4.3. Analysis of the Evolutionary Equilibrium Strategy of the Central Government. We assume that the expected revenue of the central government's strict supervision of coal mines is $E_{31}$, the expected revenue of loose supervision is $E_{32}$, and the total average expected revenue is $E_{3}$.

$$
\begin{aligned}
E_{31}= & x y\left(-C_{c}-R_{e}-R_{l}+\pi_{c}\right)+x(1-y)\left(-C_{c}-R_{e}+F_{l}+\pi_{c}\right)+ \\
& (1-x) y\left(-C_{c}+F_{e}-R_{l}\right)+(1-x)(1-y)\left(-C_{c}+F_{e}+F_{l}-D_{g}\right) \\
= & x\left(\pi_{c}-R_{e}\right)-C_{c}-y R_{l}+(1-y) F_{l}+(1-x) F_{e}-(1-x)\left(1-D_{g}\right), \\
E_{32}= & x y \pi_{c}+x(1-y) \pi_{c}+(1-x)(1-y)\left(-D_{g}\right) \\
= & x \pi_{c}-(1-x)(1-y) D_{g}, \\
E_{3}= & z E_{31}+(1-z) E_{32} .
\end{aligned}
$$



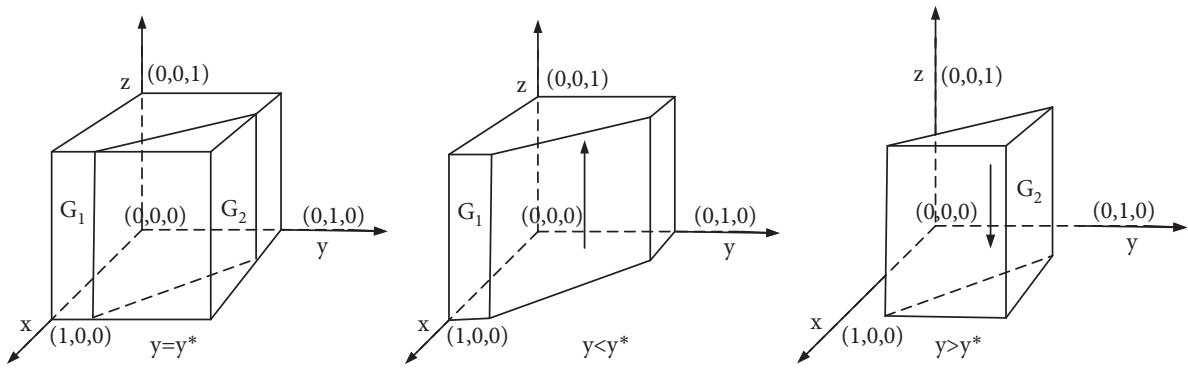

Figure 4: Central government strategy diagram.

The replicated dynamic equation of the central government is as follows:

$$
F(z)=\frac{\mathrm{d} z}{\mathrm{~d} t}=z\left(E_{31}-E_{3}\right)=z(1-z)\left[-x\left(R_{e}+F_{e}\right)-y\left(R_{l}+F_{l}\right)+F_{l}+F_{e}\right]
$$

The first derivative of the central government's replicated dynamic equation is as follows:

$$
\frac{\partial(F(z))}{\partial z}=(1-2 z)\left[-x\left(R_{e}+F_{e}\right)-y\left(R_{l}+F_{l}\right)+F_{l}+F_{e}\right]
$$

Let $J(y)=-x\left(R_{e}+F_{e}\right)-y\left(R_{l}+F_{l}\right)+F_{l}+F_{e}$.

According to the stability principle of the differential equation, the probability of the central government's strict supervision policy $z$ needs to meet the following conditions to reach a steady state: $F(z)=0$ and $\partial(F(z)) / \partial z<0$. Because $\partial(J(y)) / \partial y=-\left(R_{l}+F_{l}\right)$ and $R_{l}+F_{l}>0, J(y)$ is a decreasing function of $y$. When $y=F_{l}+F_{e}-x\left(R_{e}+F_{e}\right) / R_{l}+F_{l}=y^{*}, \quad J(y)=0, \quad$ and
$F(z) \equiv 0$, all values of $z$ will bring the central government to an evolutionarily stable state. In contrast, when $y<y^{*}$ and $J(y)>0, z=1$ is the evolutionarily stable strategy of the central government; that is, when the probability of local government coal mine safety supervision is low, the central government tends to implement a strict safety supervision policy. A diagram of the central government's strategy is shown in Figure 3.

Figure 4 shows that the probability of the central government adopting a strict supervision policy for coal mines has a volume of $G_{2}$. When $y<y^{*}, z=1$ is the central government's stable strategy. That is, the implementation of a strict supervision policy on coal mine safe production is the strategy of the central government. $V_{G_{2}}$ can be calculated as follows:

$$
V_{G_{1}}=\int_{0}^{1} \int_{0}^{1} \frac{F_{l}+F_{e}-X\left(R_{e}+F_{e}\right)}{R_{l}+F_{l}} \mathrm{~d} x \mathrm{~d} z=\frac{2 F_{l}+F_{e}-R_{e}}{2\left(R_{l}+F_{l}\right)}, \quad V_{G_{2}}=1-V_{G_{1}} .
$$

Inference 5. The probability of the central government adopting a strict supervision policy on coal safety is positively correlated with the fines imposed on local governments and coal enterprises with unsafe production. However, it is negatively correlated with rewards for coal enterprises' safe production and local governments' strict implementation of safe production supervision policies.

According to the probability formula of the central government's implementation of coal mining safety policy $V_{G_{2}}$, we obtain the first derivative of $F_{l}, F_{e}, R_{e}$, and $R_{l}$ :

$$
\begin{aligned}
& \frac{\partial V_{G_{2}}}{\partial F_{l}}>0, \\
& \frac{\partial V_{G_{2}}}{\partial F_{e}}>0, \\
& \frac{\partial V_{G_{2}}}{\partial R_{e}}<0, \\
& \frac{\partial V_{G_{2}}}{\partial R_{l}}<0 .
\end{aligned}
$$


Therefore, the increase in penalties for rent-seeking by local governments and for the unsafe production of coal mining enterprises will increase the probability of the central government formulating strict supervision. However, the first derivative of $R_{e}$ and $R_{l}$ is less than 0 , which indicates that the increase in incentives for local governments and coal mining enterprises will reduce the willingness of the central government to implement strict coal mine safety supervision policies.

Inference 6. The probability of the central government formulating a coal mine safety supervision policy is positively correlated with the probability of the local government rejecting rent-seeking from coal enterprises. When $y<y^{*}$ and $J(y)>0, z=1$ is the evolutionarily stable strategy of the central government. In contrast, when $y>y^{*}$, and $J(y)<0$, $z=0$ is the evolutionarily stable strategy of the central government, $\partial(J(x, y)) / \partial(y)<0$, indicating that the greater the probability of the local government rejecting rentseeking is, the lower the probability of the central government formulating a strict coal mine safety supervision policy becomes. The local government's strict implementation of safety supervision policy reduces the pressure of the central government to carry out strict coal mine safety supervision policy.

4.4. Analysis of the Stable State of the Tripartite Evolutionary Game. Here, we use the dynamic equilibrium of the evolutionary game and Lyapunov's method [60] to study the possible equilibrium points of the following three differential equations: (2), (7), and (13).

According to conditions $F(x)=0, F(y)=0$, and $F(z)=0$, we can obtain the equilibrium point of the game:

$$
\begin{aligned}
& F(x)=\frac{\mathrm{d} x}{\mathrm{~d} t}=x\left(E_{11}-E_{1}\right)=x(1-x)\left[z\left(R_{e}+F_{e}\right)+C_{e l}-C_{e h}+(1-y) B_{e}\right]=0, \\
& F(y)=\frac{\mathrm{d} y}{\mathrm{~d} t}=y\left(E_{21}-E_{2}\right)=y(1-y)\left[z\left(R_{l}+F_{l}\right)-(1-x) B_{e}-C_{l}\right]=0, \\
& F(z)=\frac{\mathrm{d} z}{\mathrm{~d} t}=z\left(E_{31}-E_{3}\right)=z(1-z)\left[-x\left(R_{e}+F_{e}\right)-y\left(R_{l}+F_{l}\right)+F_{l}+F_{e}\right]=0 .
\end{aligned}
$$

Eight equilibrium points can be obtained by solving the following equations:

$$
\begin{aligned}
& E_{1}(0,0,0), \\
& E_{2}(1,0,0), \\
& E_{3}(0,1,0), \\
& E_{4}(0,0,1), \\
& E_{5}(1,1,0), \\
& E_{6}(1,0,1), \\
& E_{7}(0,1,1), \\
& E_{8}(1,1,1) .
\end{aligned}
$$

The Jacobian matrix of the tripartite evolutionary game between the central government, coal enterprises, and local governments is as follows:

$$
\begin{aligned}
J & =\left[\begin{array}{lll}
a_{11} & a_{12} & a_{13} \\
a_{21} & a_{22} & a_{23} \\
a_{31} & a_{32} & a_{33}
\end{array}\right]\left[\begin{array}{lll}
\frac{\partial(F(x))}{\partial x} & \frac{\partial(F(x))}{\partial y} & \frac{\partial(F(x))}{\partial z} \\
\frac{\partial(F(y))}{\partial x} & \frac{\partial(F(y))}{\partial y} \frac{\partial(F(y))}{\partial z} \\
\frac{\partial(F(z))}{\partial x} & \frac{\partial(F(z))}{\partial y} & \frac{\partial(F(z))}{\partial z}
\end{array}\right] \\
& =\left[\begin{array}{ccc}
(1-2 x)\left[z\left(R_{e}+F_{e}\right)+C_{e l}-C_{e h}+(1-y) B_{e}\right] & -x(1-x) B_{e} & x(1-x)\left(R_{e}+F_{e}\right) \\
y(1-y) B_{e} & (1-2 y)\left[z\left(R_{l}+F_{l}\right)-(1-x) B_{e}-C_{l}\right] & y(1-y)\left(R_{l}+F_{l}\right) \\
-z(1-z)\left(R_{e}+F_{e}\right) & -z(1-z)\left(R_{l}+F_{l}\right) & (1-2 z)\left[-x\left(R_{e}+F_{e}\right)-y\left(R_{l}+F_{l}\right)+F_{l}+F_{e}\right]
\end{array}\right] .
\end{aligned}
$$


The calculated $E_{1}-E_{8}$ points can be substituted into the above Jacobian matrix to obtain the corresponding characteristic matrix. The stable state of the evolutionary game must ensure that the eigenvalues of the Jacobian matrix have nonpositive numbers. We take point $E_{1}$ as an example, and its Jacobian matrix is as follows:

$$
\left[\begin{array}{ccc}
C_{e l}-C_{e h}+B_{e} & 0 & 0 \\
0 & -B_{e}-C_{l} & 0 \\
0 & 0 & F_{l}+F_{e}
\end{array}\right]
$$

Three eigenvalues can be obtained from the matrix as follows:

$$
\begin{aligned}
& \lambda_{1}=C_{e l}-C_{e h}+B_{e}, \\
& \lambda_{2}=-B_{e}-C_{l}, \\
& \lambda_{3}=F_{l}+F_{e} .
\end{aligned}
$$

Because $F_{l}+F_{e}>0$, equilibrium point $E_{1}$ does not satisfy stable state conditions, so it is not a stable point of the tripartite evolutionary game. The corresponding eigenvalues of all eight equilibrium points are shown in Table 3 .

In this paper, the stable point of the game is analysed, and conditions for the existence of stable points are given. The results are shown in Table 4 .

Inference 7 . There are three equilibrium points when conditions (1), (2), and (3) are satisfied, and they are $E_{2}(1,0,0)$, $E_{4}(0,0,1)$, and $E_{6}(1,0,1)$. This shows that when coal enterprises choose safe production, local governments' stable strategy is to not implement strict supervision policy, and the central government will also choose relatively a loose supervision policy. In contrast, when coal enterprises choose unsafe production and local governments choose not to strictly implement the central regulatory policy, the central government will carry out strict safe production supervision policy.

\section{Simulation Analysis}

In this section, the parameters of the model are assigned based on the replicated dynamic equations (2), (6), and (10). Relevant statistical data from the China Energy Statistical Yearbook, China Statistical Yearbook, and Baodian coal mine are used. The Baodian coal mine is an affiliated mine of Yanzhou Coal Mining Co., Ltd. It was completed and put into operation in 1986, and it has more than 10000 employees. The annual output value is approximately 2.5 billion RMB. The mine's approved annual production capacity has reached 6.4 million tons, and it includes a modern coal washing plant of the same capacity. The coal field spans Zoucheng and Yanzhou. The main coal products produced are raw and washed coal. The values of the parameters of the simulation analysis mainly come from of Yanzhou Coal Mining Co., Ltd reports. Since the values of some variables are interval values, their average value is used for convenience. We use MATLAB for our following analysis:

$$
\begin{aligned}
R_{e} & =17, \\
F_{e} & =5, \\
C_{e l} & =35, \\
C_{e h} & =60, \\
B_{e} & =1.4, \\
R_{l} & =7, \\
F_{l} & =3, \\
\pi_{e} & =83 .
\end{aligned}
$$

We assume that in the initial state, the corresponding probability value is $x=0.5 ; y=0.5$; and $z=0.5$. The influence of the change in each parameter on the three parties' selection probability is analysed.

5.1. Effect of the Change of the Central Government's Reward for Local Governments and Coal Enterprises. The central government's incentives for coal production enterprises and local governments are measured as $R_{l}$ and $R_{e}$, and impacts of changes in government incentives on the strategic decisions of the central government, coal enterprises, and local governments are shown in Figure 4. In this paper, values of 17, 20 , and 23 are assigned to $R_{e}$ and values of 7,10 , and 13 are assigned to $R_{l}$.

The graph on the left of Figure 5 shows the effect of central government reward changes. From the figure, we can see that with an increase in the central government's reward for coal enterprises, the probability of safe production by coal enterprises as indicated by the corresponding lines also increases, and the probability gradually approaches 1 . At the same time, the time needed for the probability of safe production to tend to 1 grows shorter and shorter. However, with a continuous increase in reward, the willingness of the central government to reward gradually decreases, which indicates that with a gradual increase in the cost of the central government's reward, the central government becomes increasingly reluctant to reward coal enterprises for safe production.

Similarly, the graph on the right shows that with an increase in the reward for local governments, the probability of local governments strictly implementing coal safety supervision gradually increases and tends toward 1 , and the time to 1 gradually decreases. Moreover, with an increase in willingness to supervise, positive feedback is obtained, and the probability of coal enterprises carrying out safe production gradually increases. However, with continuous increase in reward, the willingness of the central government to reward as indicated by the lines gradually decreases, which indicates that with a gradual increase in the cost of the central government's safety supervision, the central government becomes increasingly reluctant to reward coal companies and local governments.

\subsection{Effect of the Change in the Central Government's Fine on} Local Governments and Coal Enterprises. The left side of Figure 6 shows the impact of the fine imposed by the central 
TABLE 3: Eigenvalues of the Jacobian matrix corresponding to each equilibrium point.

\begin{tabular}{lccc}
\hline Equilibrium point & Eigenvalue 1 & Eigenvalue 2 & Eigenvalue 3 \\
\hline$E_{1}(0,0,0)$ & $C_{e l}-C_{e h}+B_{e}$ & $-B_{e}-C_{l}$ & $F_{l}+F_{e}$ \\
$E_{2}(1,0,0)$ & $C_{e l}-C_{e h}$ & $-C_{l}$ & $F_{l}-R_{e}$ \\
$E_{3}(0,1,0)$ & $C_{e l}-C_{e h}$ & $B_{e}+C_{l}$ & $F_{e}-R_{l}$ \\
$E_{4}(0,0,1)$ & $R_{e}+F_{e}+C_{e l}-C_{e h}+B_{e}$ & $R_{l}+F_{l}+C_{e l}-C_{l}-B_{e}$ & $\left.-F_{e}\right)$ \\
$E_{5}(1,1,0)$ & $C_{e h}-C_{e l}$ & $C_{l}$ & $R_{e}-F_{l}$ \\
$E_{6}(1,0,1)$ & $-\left(R_{e}+F_{e}+C_{e l}-C_{e h}+B_{e}\right)$ & $R_{l}+F_{l}-C_{l}$ & $R_{l}-F_{e}$ \\
$E_{7}(0,1,1)$ & $R_{e}+F_{e}+C_{e l}-C_{e h}$ & $B_{e}+C_{l}-R_{l}-F_{l}$ & $R_{l}+R_{e}$ \\
$E_{8}(1,1,1)$ & $-\left(R_{e}+F_{e}+C_{e l}-C_{e h}\right)$ & $C_{l}-R_{l}-F_{l}$ & \\
\hline
\end{tabular}

TABLE 4: Stability analysis of equilibrium points.

\begin{tabular}{lccc}
\hline Equilibrium point & Eigenvalue symbol & Stability & Condition \\
\hline$E_{1}(0,0,0)$ & $(\times,-,+)$ & Unstable point & ESS \\
$E_{2}(1,0,0)$ & $(-,-,-)$ & Unstable point & $(1)$ \\
$E_{3}(0,1,0)$ & $(-,+, \times)$ & ESS & $(2)$ \\
$E_{4}(0,0,1)$ & $(\times, \times,-)$ & Unstable point & ( \\
$E_{5}(1,1,0)$ & $(+,+,-)$ & ESS & $(3)$ \\
$E_{6}(1,0,1)$ & $(-, \times, \times)$ & Unstable point & $\backslash$ \\
$E_{7}(0,1,1)$ & $(\times, \times, \times)$ & Unstable point & \\
$E_{8}(1,1,1)$ & $(-,-,+)$ & $\backslash$ \\
\hline
\end{tabular}

Note. $\times(1): F_{l}-R_{e}<0$; condition (2): $\left.R_{e}+F_{e}+C_{e l}-C_{e h}+B_{e}\right)<0 ; R_{l}+F_{l}+C_{e l}-C_{l}-B_{e}<0$; condition (3) $-\left(R_{e}+F_{e}+C_{e l}-C_{e h}+B_{e}\right)<0 ; R_{l}+F_{l}-C_{l}<0$; $R_{e}-F_{l}<0$.
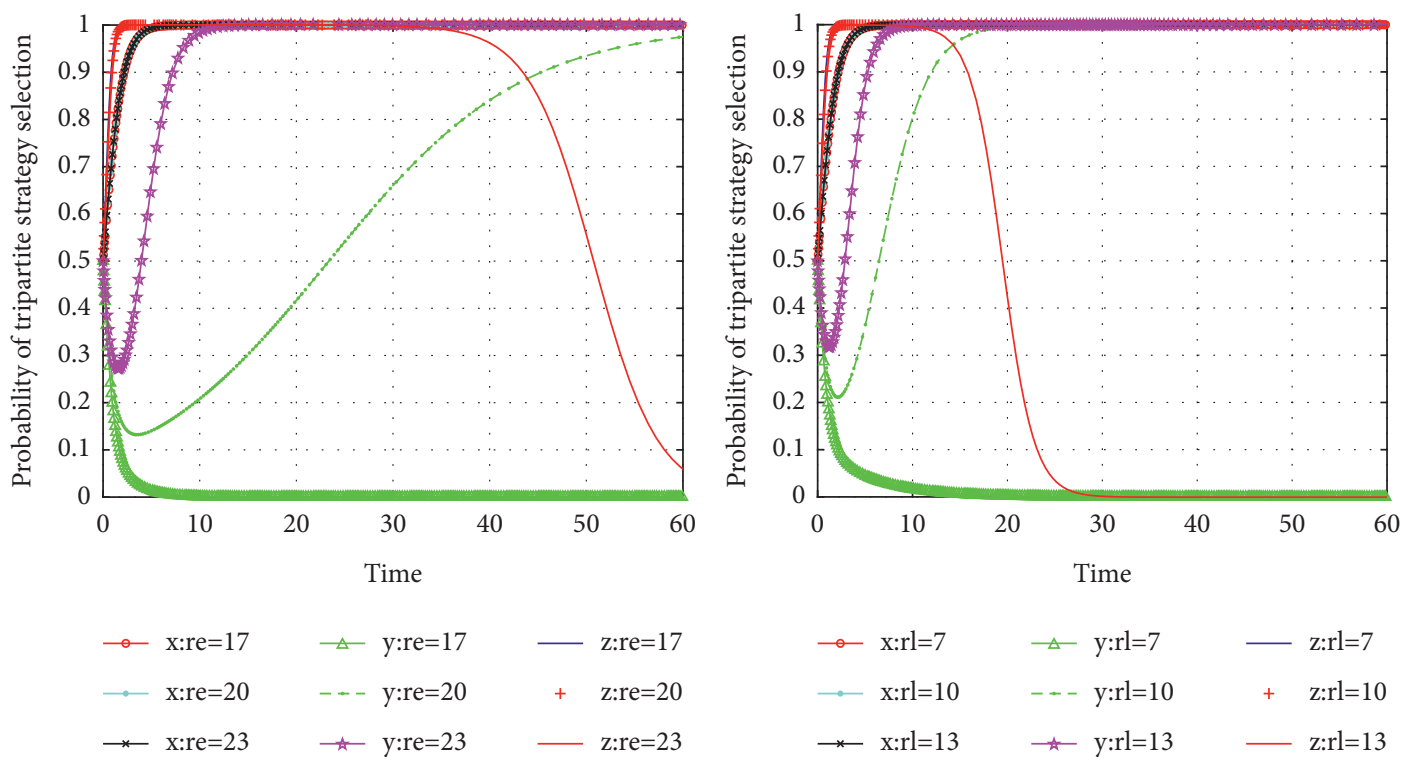

Figure 5: Effect of central government rewards for coal enterprises and local governments.

government on the coal enterprises under the tripartite evolutionary game strategy. When the central government's penalty for coal enterprises gradually increases from 5 to 9 , the probability of safe production by coal enterprises gradually increases from 0 to 1 , and the time to 1 gradually decreases. On the right is the effect of the change in penalty imposed by central government on local governments. With increasing fines on local governments, the probability of local governments choosing to strictly safety supervision policy gradually increases, and the probability of coal enterprises' safe production also gradually increases.
5.3. Effect of Production Cost Changes of Coal Enterprises. The left side of Figure 7 shows the influence of the cost change of coal enterprises on the strategy of the tripartite evolutionary game. When the safe production cost of coal enterprises gradually increases from 60 to 90 , the probability of safe production by coal enterprises gradually decreases and the time to zero gradually decreases, which indicates that the increase in the safe production cost of coal enterprises reduces the willingness to adopt safe production. On the right side is the impact of the change in unsafe production costs, from which we find that the increase in the 

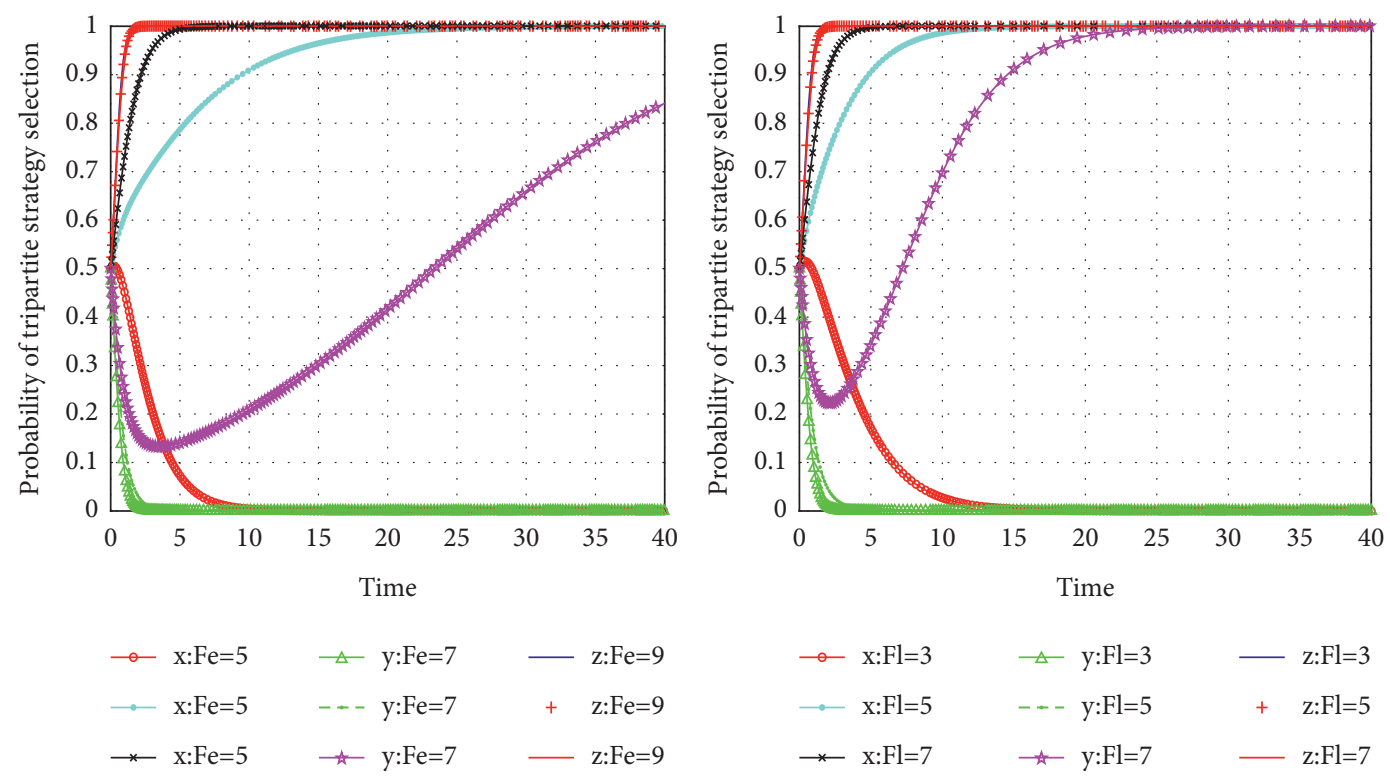

Figure 6: Effect of central government fines on coal enterprises and local governments.
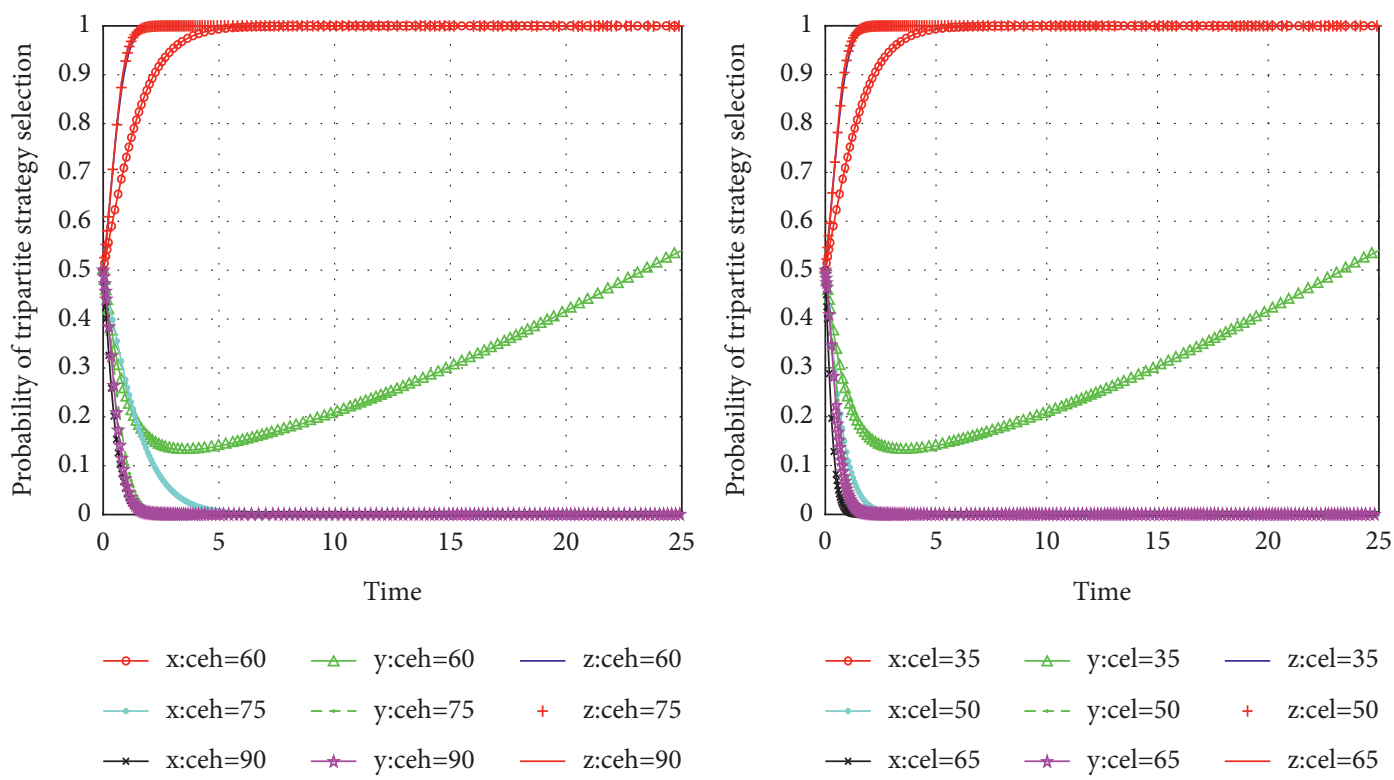

Figure 7: Effect of safe production cost changes of coal enterprises.

unsafe production costs of coal enterprises reduces enterprises' income and willingness to engage in safe production.

5.4. Effect of Changes in the Rent-Seeking and Income of Coal Enterprises. Figure 8 shows the impact of rent-seeking and income changes of coal enterprises. From this, we can see that the path of the relevant game player's strategy changes under different circumstances.

The left side of Figure 8 shows the influence of the change in the rent-seeking cost on the tripartite evolutionary game strategy. When the rent-seeking cost of the coal enterprise gradually increases from 1.4 to 2.4 , the probability of safe production as indicated by the curves undergoes almost no change. Similarly, the corresponding line shows that with an increase in rent-seeking, local governments' willingness to implement strict supervision gradually decreases and tends to 0 . On the right side is the impact of changes in coal enterprises' product sales revenue, from which we find that with an increase in sales revenue, the willingness of coal enterprises to engage in safe production gradually increases.

5.5. Three-Dimensional Graph Analysis of the Effect of Related Parameter Changes. Figure 9 shows the impact of the coal enterprise's safe production reward on the tripartite evolutionary game strategy. To analyse the impact of safe production rewards on the game process, the dynamic 

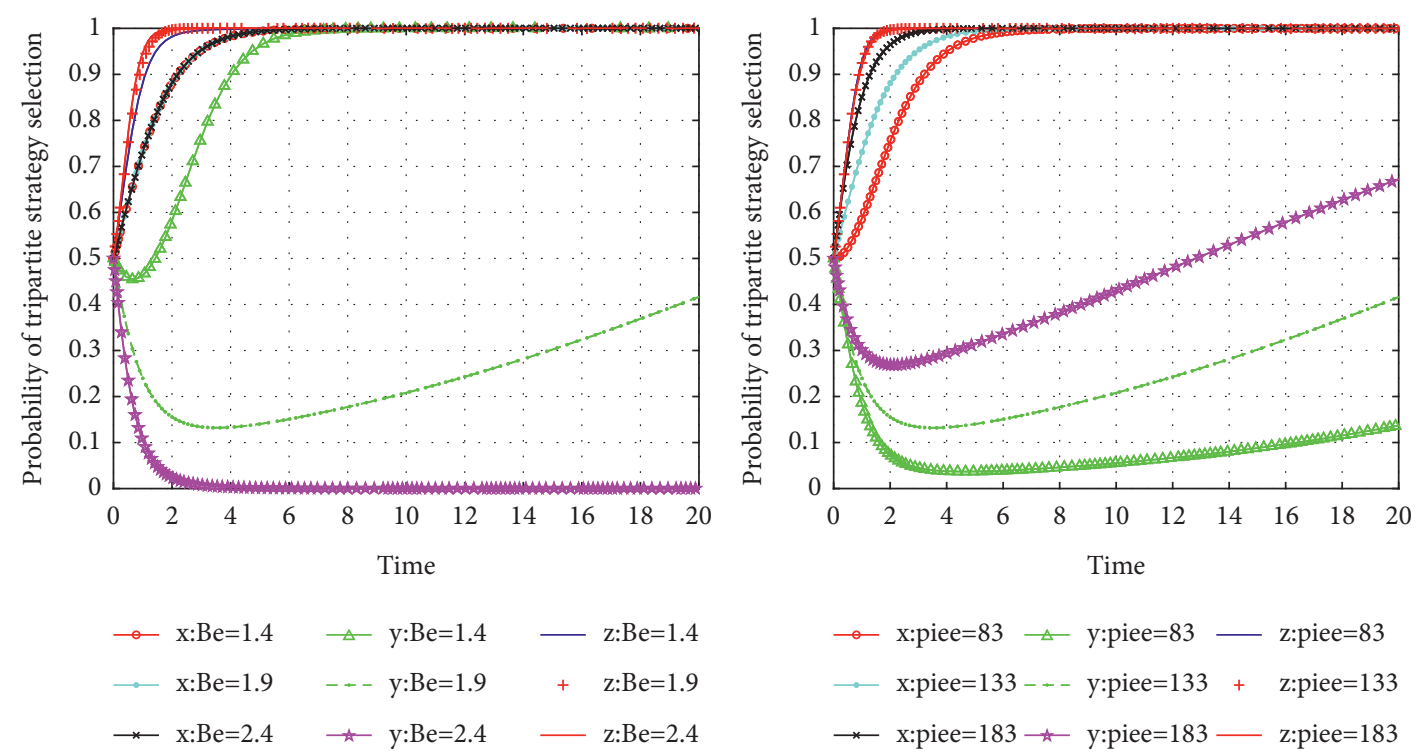

Figure 8: Effect of rent-seeking and profit changes.

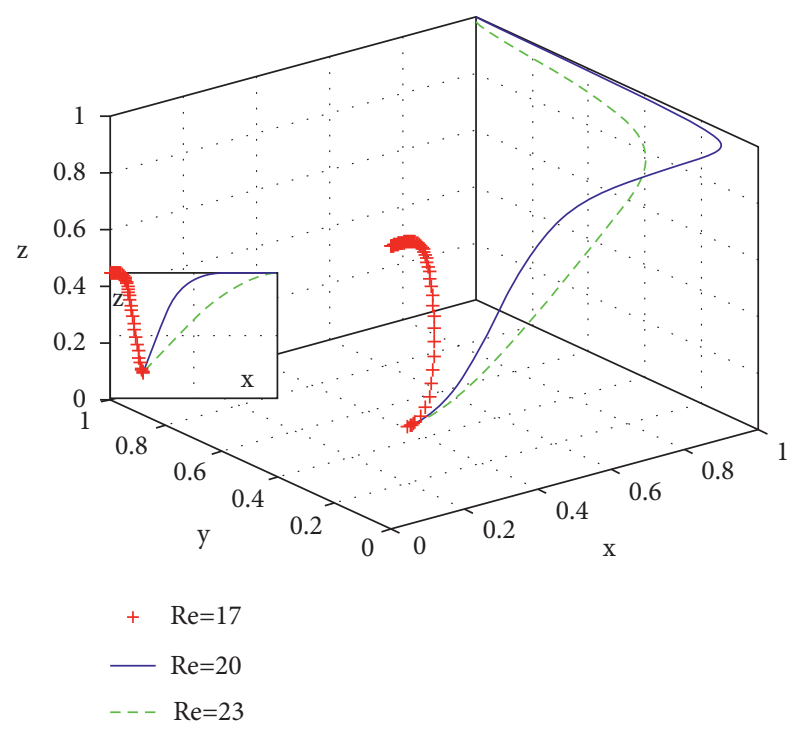

FIGURE 9: Influence of rewards on coal enterprises' safe production.

equations are copied to perform 50 time-varying simulation analyses.

Figure 9 shows that with an increase in the central government's reward for the safe production of coal enterprises, the probability of safe production by coal enterprises gradually increases, and the need for strict supervision by local governments also begins to decline. However, the increase in reward will gradually increase the burden on the central government, and the probability of the central government's probability of reward gradually decreases.

Figure 10 shows the influence of the change in sales revenues of coal enterprises on the strategies of the three parties participating in the game. The figure shows that with the gradual increase in sales revenue, the willingness of coal enterprises to carry out safe production gradually increases. Thus, the probability of the government implementing strict

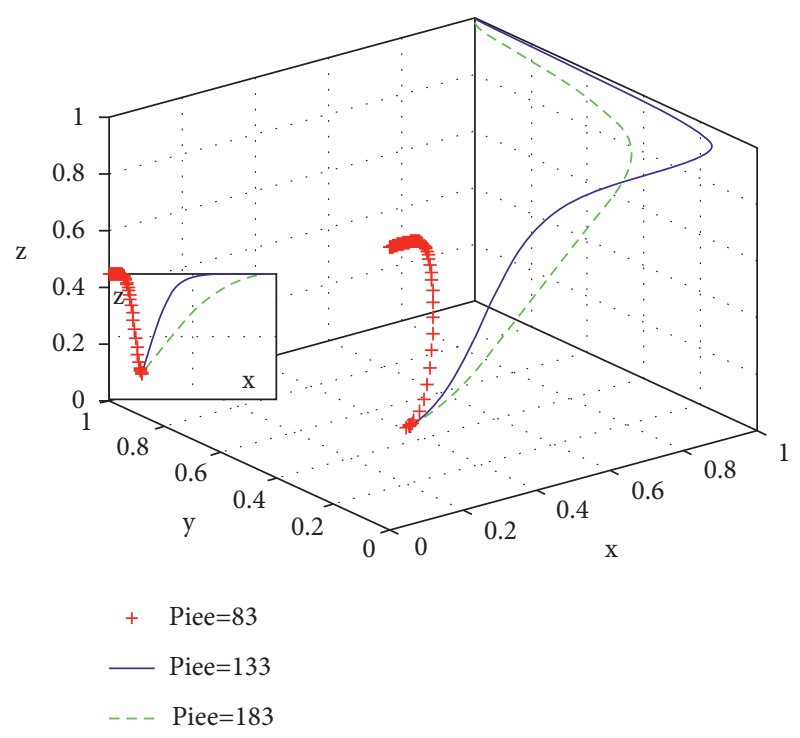

Figure 10: Analysis of changes in the sales revenue of coal enterprises.

safety supervision is gradually reduced, which is conducive to promoting safe production by coal enterprises.

Figure 11 presents an analysis of the central government's punishment of local governments that accept rentseeking from coal enterprises. The willingness of local governments to supervise gradually increases with increasing punishment from 3 to 7 . This shows that punishing local governments for accepting rent-seeking from coal enterprises encourages local governments to strengthen their supervision of safe production, and the increase in punishment motivates the central government to implement strict regulatory policy.

Figure 12 presents an analysis of the incentivizing effect of the central government on the local government's implementation of safe production supervision. The 


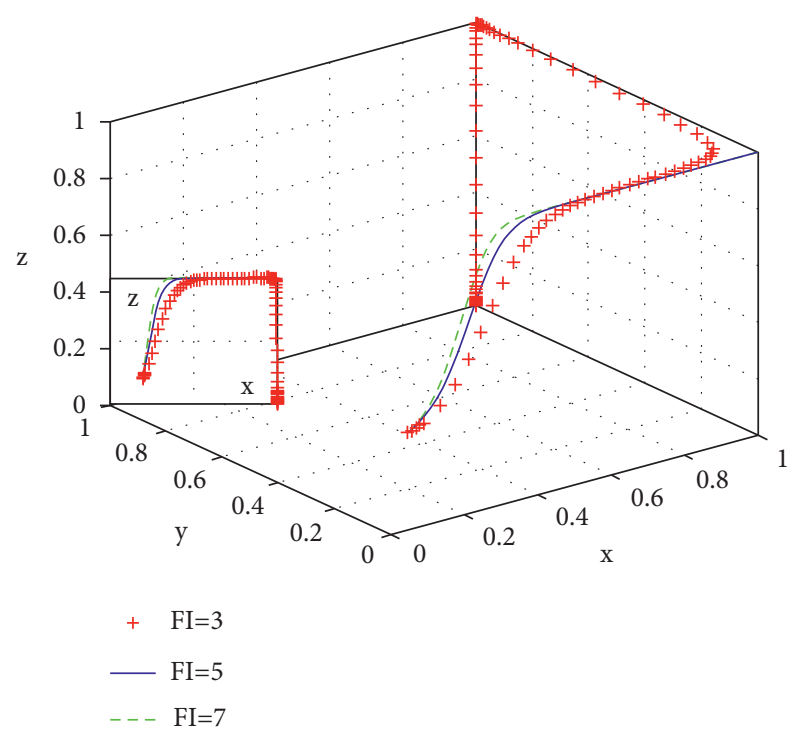

FIGURE 11: Effect of the penalty on local governments.

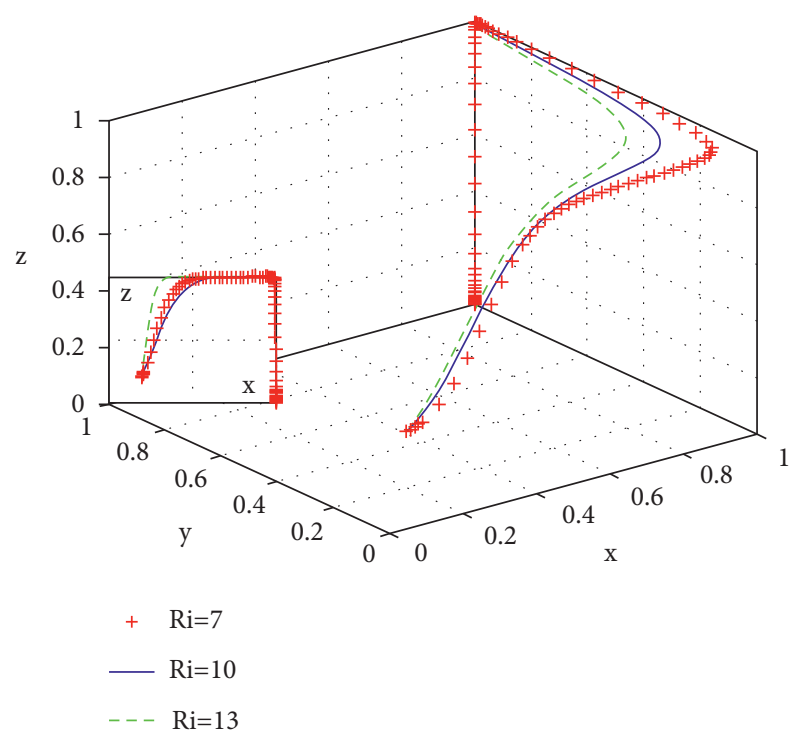

Figure 12: Analysis of the effect of the reward for local government's strict law enforcement.

willingness of the local government to implement coal mine safe production supervision increases when the incentive increases from 7 to 13 . This shows that an increase in the local government's law enforcement incentive is conducive to safe coal mine production. The probability of safe production by coal enterprises will then also improved. The increased incentive will also reduce the willingness of the central government to implement incentive policy.

\section{Conclusion and Policy Implication}

In this paper, coal production enterprises, local governments, and central government are analysed under an evolutionary game model, a replication dynamic equation for the model is established, and the stability of the evolutionary game is analysed. On this basis, the parameters of the replication dynamic equation are analysed, and the influence of a change in the parameters on the equilibrium strategy is analysed. Two- and three-dimensional diagrams are used to analyse the influence of the central government's reward and punishment on coal mining enterprises and local governments. The main conclusions of this paper are as follows:

(1) The central government's reward for coal mining enterprises' adoption of safe production can encourage coal mining enterprises to adopt safe production methods. With an increase in the central government's reward for coal enterprises, the probability of safe production also increases; however, with a continuous increase in rewards, the willingness of the central government to reward gradually decreases, which indicates that with a gradual increase in the central government's rewards, it becomes more and more reluctant to reward coal enterprises for safe production.

Similarly, with an increase in rewards given to local governments, the probability of local governments strictly implementing coal safety supervision policy gradually increases; however, with a continuous increase in rewards, the willingness of the central government to reward gradually decreases, which indicates that with a gradual increase in central government costs, the central government becomes increasingly reluctant to reward local governments. Only when the reward exceeds the cost of safe production of coal enterprises and the strict law enforcement of local governments can the enthusiasm of enterprises and local governments be improved.

(2) Punishment for the unsafe production behaviour of coal mining enterprises and rent-seeking behaviour of local governments can have the same effect. It is helpful to encourage local governments to strictly enforce the law by punishing local governments that accept corruption and rent-seeking from coal enterprises. With an increasing number of fines on local governments and coal enterprises, the probability of local governments choosing to strictly implement safety supervision gradually increases, and the probability of safe production by coal enterprises also gradually increases.

(3) When the safe production costs of coal enterprises gradually increase, the probability of safe production by coal enterprises gradually decreases, and the increase in the safe production cost of coal enterprises reduces willingness to adopt safe production. When the rent-seeking cost of coal enterprises gradually increases, the probability of safe production undergoes almost no change. Similarly, with an increase in rent-seeking, local governments' willingness to implement strict supervision gradually decreases. 
With an increase in the sales revenue of coal enterprises, such enterprises gradually become more willing to adopt safe production.

This paper only considers a game involving the central Chinese government, coal enterprises, and local governments without considering other stakeholders or the influence of game ordering and initial parameter values on game results. Therefore, in the future, we plan to consider more stakeholders, build more game models, conduct dynamic and repeated games, research the influence of various factors on the game, and thus obtain more innovative results.

\section{Data Availability}

The datasets used or analysed during the current study are available from the corresponding author on reasonable request.

\section{Conflicts of Interest}

The authors declare that there are no conflicts of interest.

\section{Authors' Contributions}

K.Z. and Q.W. conceptualized the study; K.Z. developed methodology; K.Z. provided software; K.Z. and Q.W. validated the study; K.Z. performed formal analysis; K.Z. and J.T. investigated the study; Q.W. was responsible for data curation; K.Z. and Q.W. wrote and prepared the original draft; K.Z. reviewed and edited the manuscript; Q.W. visualized the study; K.Z. supervised the study. All authors have read and agreed to the published version of the manuscript.

\section{Acknowledgments}

This research was funded by the National Natural Science Foundation of China (72061014).

\section{References}

[1] S. Niu, "Coal mine safety production situation and management strategy," Management \& Engineering, vol. 14, pp. 78-82, 2014.

[2] H. Chen, Q. Feng, R. Long, and H. Qi, "Focusing on coal miners' occupational disease issues: a comparative analysis between China and the United States," Safety Science, vol. 51, no. 1, pp. 217-222, 2013.

[3] Q. Liu, X. Li, and M. Hassall, "Regulatory regime on coal Mine Safety in China and Australia: comparative analysis and overall findings," Resources Policy, vol. 54, 2019.

[4] A. W. Homer, "Coal mine safety regulation in China and the USA," Journal of Contemporary Asia, vol. 39, no. 3, 2009.

[5] D. Yang, "The main adjustment of new version China's "coal mine safety regulations"," International Journal of Oil, Gas and Coal Engineering, vol. 7, no. 2, 2019.

[6] S. Han, H. Chen, R. Long, H. Qi, and X. Cui, "Evaluation of the derivative environment in coal mine safety production systems: case study in China," Journal of Cleaner Production, vol. 143, pp. 377-387, 2017.
[7] S.-S. Chen, J.-H. Xu, and Y. Fan, "How to improve the regulatory performance of the provincial administrations of coal mine safety in China: a grey clustering assessment based on centre-point mixed triangular whitenisation weight function," International Journal of Global Energy Issues, vol. 39, no. 6, 2016.

[8] S. Li, Y. Wang, and Q. Liu, "A model of unsafe behavior in coal mines based on game theory," International Journal of Mining Science and Technology, vol. 23, no. 1, 2013.

[9] Z. Fa and X. Li, "From aggregate to part: study on the change of coal mine safety records in China under the intervention of risk pre-control management system," Resources Policy, vol. 73, 2021.

[10] N. P. Anastasopoulos and M. P. Anastasopoulos, "The evolutionary dynamics of audit," European Journal of Operational Research, vol. 216, no. 2, 2011.

[11] S. Dutta, S. P. Sarmah, and S. K. Goyal, "Evolutionary stability of auction and supply chain contracting: an analysis based on disintermediation in the Indian tea supply chains," European Journal of Operational Research, vol. 207, no. 1, 2010.

[12] T. Xiao and G. Chen, "Wholesale pricing and evolutionarily stable strategies of retailers with imperfectly observable objective," European Journal of Operational Research, vol. 196, no. 3, 2008.

[13] J. M. Smith and G. R. Price, "The logic of animal conflict," Nature, vol. 246, no. 5427, pp. 15-18, 1973.

[14] R. M. Axelrod, "The evolution of cooperation," European Journal of Operational Research, vol. 22, 1985.

[15] R. Axelrod and D. Dion, "The further evolution of cooperation," Science (New York, N.Y.), vol. 242, no. 4884, p. 1385, 1988.

[16] S. Babu and U. Mohan, "An integrated approach to evaluating sustainability in supply chains using evolutionary game theory," Computers \& Operations Research, vol. 89, pp. 269-283, 2018.

[17] R. Chiong and J. Jovanovic, "Collaborative learning in online study groups: an evolutionary game theory perspective," Journal of Information Technology Education: Research, vol. 11, pp. 081-101, 2012.

[18] X. Deng, D. Han, J. Dezert, Y. Deng, and Y. Shyr, "Evidence combination from an evolutionary game theory perspective," IEEE Transactions on Cybernetics, vol. 46, no. 9, pp. 20702082, 2016.

[19] H. Long, H. Liu, X. Li, and L. Chen, “An evolutionary game theory study for construction and demolition waste recycling considering green development performance under the Chinese government's reward-penalty mechanism," International Journal of Environmental Research and Public Health, vol. 17, no. 17, 2020.

[20] X. Li, R. Huang, J. Dai, J. Li, and Q. Shen, "Research on the evolutionary game of construction and demolition waste (CDW) recycling units' green behavior, considering remanufacturing capability," International Journal of Environmental Respect of Public Health, vol. 18, no. 17, 2021.

[21] R. Mahmoudi and M. Rasti-Barzoki, "Sustainable supply chains under government intervention with a real-world case study: an evolutionary game theoretic approach," Computers \& Industrial Engineering, vol. 116, pp. 130-143, 2018.

[22] Z. Zou, L. Zheng, J. Huang, J. Li, and J. Wang, "Design and implementation of coal mine dust monitoring system based on cloud platform," Computer Science and Application Engineering, vol. 28, 2018. 
[23] J. T. Scholz, "Cooperative regulatory enforcement and the politics of administrative effectiveness," American Political Science Review, vol. 85, no. 1, 1991.

[24] K. Qin, Z. Jia, T. Lu et al., "The role of work engagement in the association between psychological capital and safety citizenship behavior in coal miners: a mediation analysis," International Journal of Environmental Research and Public Health, vol. 18, no. 17, 2021.

[25] Q. Liu, X. Li, W. Qiao, X. Meng, X. Li, and T. Shi, "Analysis of embedded non-safety regulation games in China's two types of coal mines through safety performance disparity, 19802014," Resources Policy, vol. 51, pp. 265-271, 2017.

[26] K. Yu, L. Zhou, Q. Cao, and Z. Li, "Evolutionary game research on symmetry of workers' behavior in coal mine enterprises," Symmetry, vol. 11, no. 2, 2019.

[27] Q. Wang, Z. Tan, G. De, Q. Tan, and L. Pu, “An evolutionary game study of clean heating promotion mechanisms under the policy regulation in China," Sustainability, vol. 11, no. 14, 2019.

[28] J. Zeng, Q. Yao, X. Wang, and Y. Zhang, "Game research on coal mine workers' off-post behaviors," Mathematical Problems in Engineering, vol. 2019, pp. 1-9, 2019.

[29] D. Liu, X. Xiao, H. Li, and W. Wang, "Historical evolution and benefit-cost explanation of periodical fluctuation in coal mine safety supervision: an evolutionary game analysis framework," European Journal of Operational Research, vol. 243, no. 3, pp. 974-984, 2015.

[30] Q. Liu, X. Li, and M. Hassall, "Evolutionary game analysis and stability control scenarios of coal mine safety inspection system in China based on system dynamics," Safety Science, vol. 80, pp. 13-22, 2015.

[31] X. Gao, J. Shen, W. He et al., "An evolutionary game analysis of governments' decision-making behaviors and factors influencing watershed ecological compensation in China," Journal of Environmental Management, vol. 251, Article ID 109592, 2019.

[32] X. Wang, R. Lu, H. Yu, and D. Li, "Stability of the evolutionary game system and control strategies of behavior instability in coal mine safety management," Complexity, vol. 2019, Article ID 6987427, 14 pages, 2019.

[33] R. Lu, X. Wang, H. Yu, and D. Li, "Multiparty evolutionary game model in coal mine safety management and its application," Complexity, vol. 2018, pp. 1-10, 2018.

[34] H. Chen, Q. Feng, and J. Cao, "Rent-seeking mechanism for safety supervision in the Chinese coal industry based on a tripartite game model," Energy Policy, vol. 72, pp. 140-145, 2014.

[35] Y. Wang, D. Wang, and X. Shi, "Exploring the dilemma of overcapacity governance in China's coal industry: a tripartite evolutionary game model," Resources Policy, vol. 71, 2021.

[36] M. You, S. Li, D. Li, Q. Cao, and F. Xu, "Evolutionary game analysis of coal-mine enterprise internal safety inspection system in China based on system dynamics," Resources Policy, vol. $67,2020$.

[37] L. Ma, Q. Liu, Z. Qiu, and Y. Peng, "Evolutionary game analysis of state inspection behaviour for coal enterprise safety based on system dynamics," Sustainable Computing: Informatics and Systems, vol. 28, 2020.

[38] K. Jiang, D. You, R. Merrill, and Z. Li, "Implementation of a multi-agent environmental regulation strategy under Chinese fiscal decentralization: an evolutionary game theoretical approach," Journal of Cleaner Production, vol. 214, pp. 902-915, 2019.
[39] J. Liu, C. Wang, X. Wang, Q. Li, and H. Garg, "Behavior choice of game parties under the interference of cognition in the game between coal miners and supervisors," Mathematical Problems in Engineering, vol. 2021, Article ID 5592025, 13 pages, 2021.

[40] X. Yang, Y. Tian, K. Feng, J. Yang, S.-h. Zhang, and S. Wang, "Signal game analysis on the effectiveness of coal mine safety supervision based on the affective events theory," Complexity, vol. 2020, Article ID 5592025, 9 pages, 2020.

[41] Y. Li, Y. Zhang, H. Dai, and Z. Zhao, "Game modelling and strategy research on trilateral evolution for coal-mine operational safety production system: a simulation approach," Complexity, vol. 2020, Article ID 5592025, 16 pages, 2020.

[42] Z. Sun, W. Wang, W. Zhu, L. Ma, and J. Lu, "Evolutionary game analysis of coal enterprise resource integration under government regulation," Environmental Science and Pollution Research, vol. 26, 2020.

[43] B. Fan, T. Guo, R. Xu, W. Dong, and M. B. Cheng, "Evolutionary game research on the impact of environmental regulation on overcapacity in coal industry," Mathematical Problems in Engineering, vol. 2021, Article ID 5558112, 19 pages, 2021.

[44] Y. Fang, L. Chen, S. Mei, W. Wei, S. Huang, and F. Liu, "Coal or electricity? An evolutionary game approach to investigate fuel choices of urban heat supply systems," Energy, vol. 181, 2019.

[45] A. Prashar, "A bibliometric and content analysis of sustainable development in small and medium-sized enterprises," Journal of Cleaner Production, vol. 245, 2020.

[46] Q. Wang, Q. Mei, S. Liu, Q. Zhou, and J. Zhang, "Demographic differences in safety proactivity behaviors and safety management in Chinese small-scale enterprises," Safety Science, vol. 120, pp. 179-184, 2019.

[47] R. Tong, Y. Yang, X. Ma, Y. Zhang, S. Li, and H. Yang, "Risk assessment of miners' unsafe behaviors: a case study of gas explosion accidents in coal mine, China," International Journal of Environmental Research and Public Health, vol. 16, no. 10, 2019.

[48] Y. Li, B. Zhang, B. Wang, and Z. Wang, "Evolutionary trend of the coal industry chain in China: evidence from the analysis of I-O and APL model," Resources, Conservation \& Recycling, vol. 145, 2019.

[49] V. Bagodi and B. Mahanty, "Shifting the burden archetype: developing a system dynamics game," Journal of Modelling in Management, vol. 10, no. 3, 2015.

[50] P.-P. J. Fernando, P. J. Felipe, and S.-G. Jakeline, "A system dynamics model: transition to sustainable processes," Technology in Society, vol. 65, 2021.

[51] Z. Wu and R. Zheng, "Research on the impact of financial transmission rights on transmission expansion: a system dynamics model," Energy, vol. 239, 2022.

[52] Y. Yang and W. Yang, "Does whistleblowing work for air pollution control in China? A study based on three-party evolutionary game model under incomplete information," Sustainability, vol. 11, no. 2, 2019.

[53] L. B. V. Alves and L. H. A. Monteiro, "A spatial evolutionary version of the ultimatum game as a toy model of income distribution," Communications in Nonlinear Science and Numerical Simulation, vol. 76, 2019.

[54] S. Shibasaki, "The evolutionary game of interspecific mutualism in the multi-species model," Journal of Theoretical Biology, vol. 471, pp. 51-58, 2019.

[55] D. Peter, "Evolutionary stable strategies and game dynamics," Elsevier, vol. 40, no. 1-2, 1978. 
[56] G. Carmona and K. Podczeck, "Existence of Nash equilibrium in ordinal games with discontinuous preferences," Economic Theory, vol. 61, no. 3, 2016.

[57] F. Tramontana, A. A. Elsadany, B. Xin, and H. N. Agiza, "Local stability of the Cournot solution with increasing heterogeneous competitors," Nonlinear Analysis: Real World Applications, vol. 26, 2015.

[58] S.-S. Chen, J.-H. Xu, and Y. Fan, "Evaluating the effect of coal mine safety supervision system policy in China's coal mining industry: a two-phase analysis," Resources Policy, vol. 46, pp. 12-21, 2015.

[59] H. Shan and J. Yang, "Sustainability of photovoltaic poverty alleviation in China: an evolutionary game between stakeholders," Energy, vol. 181, 2019.

[60] D. Friedman, "On economic applications of evolutionary game theory," Journal of Evolutionary Economics, vol. 8, no. 1, 1998. 